\title{
AS RELIGIÕES COMO FORCES PROFONDES NAS RELAÇÕES INTERNACIONAIS
}

\author{
Evanildo Costeski ${ }^{1}$
}

\begin{abstract}
Resumo:
No presente texto, utilizamos o conceito de forces profondes, desenvolvido pelo historiador francês Pierre Renouvin (1893-1974), para falar da influência das religiões nas Relações Internacionais. É verdade que Renouvin considerava ser praticamente impossível compreender historicamente o sagrado religioso. Todavia, como salientou Robert Frank (1944 -), ao se falar da religião, não se deve focar apenas no aspecto transcendental da fé. A religião faz parte da cultura humana e, como tal, não pode ser desprezada pelo historiador das Relações Internacionais. O conceito de force profonde pode representar a religião de forma positiva ou negativa. Na presente análise, buscaremos salientar os valores positivos e universais das religiões.
\end{abstract}

Palavras-Chaves: Religião. Política. Relações Internacionais.

\section{RELIGIONS AS FORCES PROFONDES IN INTERNATIONAL RELATIONS}

\begin{abstract}
:
In this paper, we use the concept of forces profondes, developed by the french historian Pierre Renouvin (1893-1974), to talk about the influence of religion in International Relations. It is true that Renouvin considered to be virtually impossible to historically understand the religious sacred. However, as pointed Robert Frank (1944), when one speaks about religion, one should not focus only on the transcendental aspect of faith. Religion is part of human culture and, as such, cannot be neglected by the historian of International Relations. The concept of force profonde can represent religion in a positive or negative way. In this analysis, we will seek to highlight the positive and universal values of religions.
\end{abstract}

Key Words: Religion. Politics. International Relations.

\section{Introdução}

Dentre todas as disciplinas sociais, a Teoria das Relações Internacionais é certamente a mais "ateia", a mais distante das experiências religiosas: é como se a exclusão da religião estivesse escrito em seu código genético (HATZOPOULOS; PETITO, 2006, p. 3). Jonathan Fox (2006) constata que "a ignorância da religião é uma tendência geral das ciências sociais ocidentais e sobretudo dos cursos universitários de Relações Internacionais" (p. 1060). Isso se deve sobretudo ao fato de as Relações Internacionais modernas terem sua origem no tratado de Westfália, que pôs fim às guerras religiosas em 1648 .

\footnotetext{
${ }^{1}$ Pós-doutor pelo Centro de História e Cultura da Universidade Nova de Lisboa. Doutor em Filosofia pela Pontifícia Universidade Gregoriana, Roma. Professor Associado do Instituto de Cultura e Arte da Universidade Federal do Ceará. Email: evanildoc@uol.com.br.
} 
Para o sistema pós-westfaliano, as religiões, quando levadas para o campo das Relações Internacionais, geram intolerâncias, guerras, devastações e insurreições políticas, até provocar o colapso da ordem internacional. Deve-se, por isso, separar o Estado das Religiões. A privatização da religião e a secularização da política tornam-se instrumentos indispensáveis para reduzir os conflitos religiosos e por fim à função destrutiva e sanguinária da religião nas Relações Internacionais (THOMAS, 2006, p. 35). O Estado passa a ser visto como elemento racional, a serviço do esclarecimento, em oposição aos sentimentos violentos e irracionais das religiões. Em suma, para o Estado moderno, as religiões pertenceriam a uma época das trevas felizmente superada pela modernidade.

Não se esperava, portanto, que as religiões assumissem novamente o protagonismo no sistema internacional. Foi de fato uma surpresa a revolução islâmica iraniana em 1979 e, de certa forma, o próprio ataque às torres gêmeas em 2001. Nem mesmo o grande debate em torno do livro de Samuel. P. Huntington (1996) no final do século XX parece ter sensibilizado os principais teóricos das Relações Internacionais. Uma pesquisa feita em quatro grandes revistas de Relações Internacionais mostrou que de 1600 artigos publicados de 1980 a 1999, apenas seis tinham a religião como objeto de estudo (PHILPOTT apud FOX, 2006, nota 09, p. 1062).

Atualmente, a situação está mudando. Vários teóricos têm se dedicado ao tema das Religiões nas Relações Internacionais ${ }^{3}$. Todos concordam que não é mais possível compreender os acontecimentos do mundo sem as religiões. Fale-se, inclusive, da necessidade de se pensar uma teologia política internacional (KUBÁLKOVÁ, 2006, p. 99-133). Mas, podemos perguntar: estão de fato as teorias clássicas das relações Internacionais preparadas para acolher as religiões em suas análises? Tradicionalmente, o Realismo se concentra mais sobre as forças materiais, deixando pouco espaço para outros motivos que poderiam explicar o comportamento dos Estados; todavia, isso não impede que a religião possa ser considerada como um poder essencial da realpolitik. Para os marxistas, a religião foi vista como um "ópio do povo"; entretanto, isso não retira igualmente sua importância social. O Construtivismo, ao defender que a estrutura é constituída pelo homem, poderia dar um espaço mais determinante ao fator religioso;

2 As revistas estudadas por Daniel Philpott foram International Organization, International Studies Quartely, International Security e Words Politics, cf. Fox (2006, nota 08, p. 1062).

${ }^{3}$ Ver, por exemplo, os livros organizados por P. Hatzopoulos e F. Petito (2006) e V. Coralluzzo e L. Ozzano (2012).

\begin{tabular}{|l|l|l|l|l|}
\hline Qevista Dialeatus & Ano 4 & n. 11 & Agosto - Dezembro 2017 & p. 297 - 309 \\
\hline
\end{tabular}


mas poucos teóricos têm feito isso. É verdade que a Escola Inglesa, desde o seu início, no final dos anos 50, soube reconhecer nos diversos movimentos culturais - incluindo aí a religião - uma força considerável na formação da sociedade internacional (THOMAS, 2006, p. 44-45). Todavia, infelizmente, temos que dar razão a Jonathan Fox: "é certamente bem mais simples proclamar que a religião deveria ser integrada à Teoria das Relações Internacionais do que integrá-la efetivamente” (2006, p. 1071).

\section{Religião e forças profundas em Pierre Renouvin}

Para tentar entender melhor a influência das religiões nas Relações Internacionais, utilizaremos o importante conceito de forces profondes, desenvolvido pelo historiador francês das Relações Internacionais Pierre Renouvin. Será esse conceito que nos permitirá falar da ação positiva das religiões na política mundial. Pierre Renouvin elabora o conceito de forces profondes no livro Introdução à história das Relações Internacionais, publicado com seu discípulo Jean-Baptiste Duroselle em 1964. Contudo, é importante frisar que esse conceito já está presente em seu importante livro sobre a História da Primeira Guerra Mundial, publicado em 1934, quando afirma que: “de um lado, são as tradições históricas, as condições geográficas e as orientações sentimentais e, de outro lado, as preocupações econômicas, que dão às relações entre as grandes potências sua fisionomia nesses primeiros anos do século XX" (RENOUVIN, 1948, p. 131) $)^{4}$.

Mas o que seriam as forces profondes? Além das relações propriamente ditas dos Estados, centralizadas principalmente nos homens de governo e na diplomacia, existem forças que determinam os povos e, enfim, as próprias tomadas de decisões dos homens de Estado. Essas podem ser tanto "forças materiais" - fatores geográficos, condições demográficas, forças econômicas - como "forças espirituais - sentimento nacional e sentimento pacifista -, incluído aí o sentimento religioso (RENOUVIN; DUROSELLE, 1991, p. 1-4).

Em relação ao nacionalismo, dominante na primeira metade do século $\mathrm{XX}$, Renouvin admite que as crenças religiosas põem às Relações Internacionais problemas particularmente difíceis para o historiador. Há muitas opiniões controversas e

\footnotetext{
${ }^{4}$ Sobre a história do conceito de forces profondes na Escola Francesa de Relações Internacionais, ver R. Frank (2012, p. 5-27).

\begin{tabular}{|l|l|l|l|l|}
\hline Rovista Dialectus & Ano 4 & n. 11 & Agosto - Dezembro 2017 & p. 297 - 309 \\
\hline
\end{tabular}
}


contraditórias. Muitas vezes os líderes assumem um posição e os fiéis outra. Isso vale, inclusive, para o Catolicismo. É verdade que, em princípio, o catolicismo busca se opor a todo tipo de nacionalismo, para se evitar uma guerra entre Estados católicos. Mas isso não impediu, por exemplo, que a maior parte do clero francês defendesse o nacionalismo no final do século XIX e no início do século XX e que os católicos italianos aceitassem a expansão colonial fascista na África na primeira metade do século XX. (RENOUVIN; DUROSELLE, 1991, p. 235).

As Igrejas protestantes não têm, aparentemente, os mesmos motivos que a Igreja Católica para temer o nacionalismo. Mas, pergunta Renouvin: elas foram realmente nacionalistas? É verdade que, na Alemanha, a Igreja evangélica prussiana, antes de 1914, manifestou sem reserva o ideal nacional da "grande Alemanha" ou pangermanismo, culminando, a partir de 1919 e, sobretudo, depois de 1933, na defesa do nacional-socialismo. Com exceção de uma pequena minoria, os pastores alemães deram seu apoio ao partido nacional-socialista. Na Inglaterra, a Igreja Anglicana ensinava que Deus tinha uma missão divina para a Inglaterra. O mesmo pode ser dito de algumas Igrejas americanas no final do século XIX, que afirmavam que o Estados Unidos tinham como missão cristianizar a Ásia. Porém, em todos esses casos, observa Renouvin, os defensores do nacionalismo não buscaram fundamentar-se diretamente no sentimento religioso. Bastava apenas um consentimento tácito ou mesmo uma resignação dos líderes religiosos (RENOUVIN; DUROSELLE, 1991, p. 236-237). O mesmo pode-se dizer das Igrejas Ortodoxas e de suas relações com os nacionalismos eslavos. Por isso, conclui Renouvin: não é a fé ou o sentimento religioso que conduz ao nacionalismo. São as Igrejas que se indentificam com uma ideia nacional e que se põem a serviço do Estado (RENOUVIN; DUROSELLE, 1991, p. 238).

Desse modo, apesar de reconhecer a influência da religião sobre os Estados, Renouvin evita reduzir a fé religiosa a uma posição histórica determinada. Existem uma diversidade de posições, todas se referindo à fé ou ao um tipo de sentimento religioso. Mas nenhuma dessas posições, inclusive aquelas defendidas pelos líderes religiosos, exaurem o aspecto transcendental da fé. Ele confessa ser praticamente impossível classificar o discurso religioso, pelo fato de o sagrado religioso se referir a um mundo transcendente, inacessível ao ponto de vista do historiador:

Como compreender a mentalidade religiosa de um grupo humano sem participar, por uma experiência pessoal, de suas convicções? O descrente

\begin{tabular}{|l|l|l|l|l|}
\hline Rovista Dialectus & Ano 4 & n. 11 & Agosto-Dezembro 2017 & p. $297-309$ \\
\hline
\end{tabular}


frequentemente tem a tendência de tratar com desprezo as manifestações que lhe parecem vãs ou mesmo hipócritas. E como, ao participar de tais crenças, abordar o estudo com espírito crítico, sem ser conduzido inconscientemente por pontos de vistas convencionais? Essa é uma área em que a interpretação requer mais comedimento e cautela que em outros lugares (1991, p. 234).

Percebe-se igualmente essa ambiguidade nos movimentos pacifistas modernos. Em um primeiro momento, poderia se dizer que o movimento pacifista representaria a essência do sentimento religioso. O Cristianismo, por exemplo, condena a violência e recomenda claramente a paz e a fraternidade entre os povos. Não seria isso suficiente para fazer com que os cristãos evitassem as guerras? Não sendo possível, em quais hipóteses a guerra poderia ser admitida? Temos aqui a longa discussão teológica em torno da "guerra justa". Protestantes e católicos têm respostas diferentes a essa questão: o catolicismo sempre procurou se constituir como uma força internacional e mesmo supranacional, enquanto o protestantismo demorou a assumir posições claras em nível internacional. Porém, quando decidiu agir, foi mais enfático que o próprio catolicismo. De fato, foi o protestantismo que deu início aos movimentos pacifistas e ecumênicos, ainda no século XIX. Isso não eliminou, entretanto, as diferenças teológicas e políticas entre as Igrejas protestantes. O "velho luteranismo", por exemplo, optou por reduzir o cristianismo à vida interior, abstendo-se das contingências políticas. As clássicas diferenças políticas entre a Inglaterra e os demais Estados europeus tampouco foram superadas pelos movimentos ecumênicos e pacifistas. Infelizmente, conclui Renouvin, o sentimento religioso não conseguiu se sobrepor aos interesses materiais: "o sentimento cristão de fraternidade não prevaleceu sobre o sentimento nacional" (RENOUVIN; DUROSELLE, 1991, p. 250-259).

A posição do islamismo parece ser bem diferente. Ao contrário do Cristianismo, há na doutrina islâmica uma estreita conjugação entre as forças políticas e as forças religiosas. Não existe no Islã uma distinção clara entre poder espiritual e o poder político: a "guerra santa" ou Jihad deve ser praticada por todo muçulmano. Mas isso não significa que ela deve ser permanente. Segundo a interpretação adotada por Renouvin nos anos de 1960, é interesse do Islã prever momentos de paz e, inclusive, estabelecer relações pacíficas com os demais povos (RENOUVIN; DUROSELLE, 1991, p. 238-240). Isso se observou com os novos Estados formados após o fím do Império Otomano. A própria Turquia acabou adotando a ideia de um Estado secular. Evidentemente, como a breve análise de Renouvin sobre o islamismo é limitada à primeira metade do século XX, ele não poderia prever a nova interpretação da Jihad

\begin{tabular}{|l|l|l|l|l|}
\hline Gevista Dialectus & Ano 4 & n. 11 & Agosto - Dezembro 2017 & p. $297-309$ \\
\hline
\end{tabular}


feita, por exemplo, pelo Estado Islâmico e por outros movimentos fundamentalistas hodiernos, defensores de um estado permanente de guerra.

Desse modo, as controvérsias teológicas e políticas, junto com a impossibilidade de a fé, enquanto sentimento religioso, ser classificada historicamente, fez com que Renouvin evitasse tratar a religião como um tipo específico de força profunda nas Relações Internacionais. O sentimento religioso existe como uma espécie de força auxiliar, mas não como uma força determinante.

Na segunda parte da obra, escrita por Jean-Baptiste Duroselle (1991, p. 283444), é apresentado a ação das forces profondes sobre o homem de Estado e sobre os processos de decisões do mesmo. Era de se esperar que Duroselle tratasse aqui das religiões, visto que ele já tinha estudado a ação social do catolicismo francês no século XIX em sua tese de doutoramento (1951). Mas não é isso que ele faz. A religião não é sequer mencionada na segunda parte do texto de 1964. O mesmo acontece com o livro Todo império perecerá: Teoria das Relações Internacionais, publicado em 1981 e considerado, do ponto de vista metodológico, o seu texto teórico mais relevante.

A religião tampouco merecerá atenção dos discípulos imediatos de Renouvin e Duroselle. Entre as forças profundas elencadas por Renouvin, serão as forças econômicas que dominarão o debate nos anos de 1960 e 1970, influenciadas evidentemente pelo discurso marxista dominante na época. Posterioremente, será data igualmente uma atenção especial às pressões da opinião pública (cf. FRANK, 2012, p. 17-21).

As ações religiosas na teoria francesa das Relações Internacionais terão algum destaque apenas nos trabalhos atuais de Robert Frank, professor da cátedra de História das Relações Internacionais da Universidade Paris I Panthéon-Sorbonne de 1994 a 2012, ocupada anteriormente por René Giraut, Jean-Baptiste Duroselle e Pierre Renouvin. No livro Pour l'histoire des relations internacionales (2012), Robert Frank dedica todo um capítulo ao catolicismo, protestantismo, judaísmo e islamismo, considerados como "forças profundas" nas Relações Internacionais (p. 407-435). É isso que veremos agora.

\section{As Religiões como forças profundas em Robert Frank}

Assim como Pierre Renouvin, Robert Frank admite dificuldades em relação ao tema. De fato, tratar a religião somente como um fator cultural e histórico pode levar a

\begin{tabular}{|l|l|l|l|l|}
\hline Gevista Dialectus & Ano 4 & n. 11 & Agosto - Dezembro 2017 & p. $297-309$ \\
\hline
\end{tabular}


um desprezo do sagrado religioso. Todavia, ao se falar da religião, não se pode focar apenas no aspecto transcendental da fé e, assim, desprezar os fenômenos religiosos historicamente determinados. Robert Frank considera não ser mais possível ao historiador ignorar o protagonismo das religiões nas Relações Internacionais. A religião faz parte da cultura, entendida como um "um conjunto de representações do divino e do sagrado pertencentes a um determinado grupo humano, com suas práticas rituais e produções simbólicas”. Ela tem também uma função essencial na política, porque estabelece valores e legitima a ação do cidadão. No campo internacional, as religiões são responsáveis por produzirem solidariedades e tensões entre os Estados. Elas exercem, portanto, uma força considerável sobre as Relações Internacionais, independentemente dos meios oficiais e diplomáticos (FRANK, 2012, p. 408-409). Dessa maneira, elas podem e devem ser classificadas como um tipo de força profunda específica.

Mas será que as religiões podem realmente ser reduzidas a meros fatores culturais e políticos? Como fica o sagrado religioso? As análises que Robert Frank faz do catolicismo, protestantismo, judaísmo e islamismo não escondem um certo paradoxo em cada uma dessas religiões. No catolicismo, por exemplo, existe uma clara ambigüidade entre as ações políticas e religiosas do Estado do Vaticano e da Santa Sé. Ao contrário do que se poderia pensar, é através da Santa Sé - sede do governo espiritual da Igreja - e não através do Estado do Vaticano, que os diplomatas são credenciados. O poder jurídico internacional pertence à Santa Sé, não ao Estado do Vaticano (FRANK, 2012, p. 409-411). Desse modo, é evidente que o poder espiritual se sobrepõe ao temporal, não se reduzindo a este. No caso do judaísmo, fica igualmente difícil distinguer o judeu crente do judeu laico, visto que o judaísmo se refere tanto a uma cultura religiosa ou a uma fé, como também a um conjunto de elementos não religiosos e laicos (FRANK, p. 418-419).

Mas o caso mais paradigmático é o caso do islamismo. Diferentemente de Pierre Renouvin, Robert Frank dedica mais espaço à religião islâmica (2012, p. 424435). Isso se deve, obviamente, à importância que esta adquiriu nas Relações Internacionais atuais. Logo de início, Robert Frank diz claramente que o Islã não se confunde com o islamismo. Historicamente, a religião islâmica sempre evitou ser instrumentalizada pelos movimentos políticos. Todavia, o islamismo, mesmo se distinguindo da religião islâmica, não pode ser compreendido sem o aspecto religioso.

\begin{tabular}{|l|l|l|l|l|}
\hline Gevista Dialectus & Ano 4 & n. 11 & Agosto - Dezembro 2017 & p. $297-309$ \\
\hline
\end{tabular}


O que precisa ser decifrado aqui é a relação intrínseca existente entre o islamismo e o fundamentalismo islâmico. De fato, por detrás do fundamentalismo político, existe sempre um fundamentalismo religioso. Esse é o aspecto mais instigante e sutil da análise de Robert Frank.

O fundamentalismo islâmico almeja retornar às fontes, tanto à Sharia, isto é, às regras expressas pelo Corão, como às Hadiths, ou seja, aos próprios dizeres literais de Maomé, com o objetivo de pleitear a (re)islamização da sociedade e lutar contra a modernidade ocidental. Todavia, eles não têm a pretensão de tomar o poder político. É o fundamentalismo político que irá se apoderar do fundamentalismo religioso e transformá-lo em um programa político. Como diz Robert Frank: "o islamismo é a politização do fundamentalismo". (FRANK, 2012, p. 428). Foi o que fez a Irmandade Muçulmana, o Hamas, a Al-Qaeda e, ultimamente, o Boko Haram e o Estado islâmico, só para citar alguns exemplos.

É verdade que o fundamentalismo político não é apanágio do fundamentalismo religioso islâmico. O governo republicano de George W. Bush também transformou o fundamentalismo cristão em um fundamentalismo político. Contudo, no caso do Islã, existem outros fatores, além dos religiosos. De fato, o mundo muçulmano sempre se viu como uma vítima do ocidente. Assim, o ódio generalizado aos europeus e americanos e, em particular, a questão da ocupação israelense da Palestina, visto continuamente como um símbolo do domínio ocidental, fez com que muitos muçulmanos passassem a instrumentalizar politicamente os ensinamentos religiosos (FRANK 2012, p. 431-432).

É certo que o fundamentalismo religioso é independente do fundamentalismo político e que este último tem motivos políticos que não são especificamente religiosos. Porém, sem o fundamentalismo religioso não existiria o fundamentalismo político. Bem entendido: isso não significa que o fundamentalismo religioso deva necessariamente produzir o fundamentalismo político. Contra o islamismo político, o combate deve ser no campo político; contra o fundamentalismo religioso, o combate depende de um debate teólogico, religioso, cultural e íntimo, isto é, ao nível do sentimento e das consciências individuais (FRANK, 2012, p. 428-432).

Nota-se, com isso, que há sempre um aspecto da dimensão religiosa que não pode ser restringido ao político. Como reduzir aquilo que é íntimo, que pertence exclusivamente à fé, a uma pura abordagem cultural e política? Em nossa opinião, Robert Frank não conseguiu cumprir o que se propôs no início de seu texto, a saber:

\begin{tabular}{|l|l|l|l|l|}
\hline Gevista Dialectus & Ano 4 & n. 11 & Agosto - Dezembro 2017 & p. $297-309$ \\
\hline
\end{tabular}


conceber o religioso apenas como um fator social e cultural, independentemente do aspecto sagrado e transcendental.

Para se determinar corretamente a ação das religiões no sistema politico é preciso manter sempre a dialética entre o sagrado e o profano, entre o transcendente e o imanente e, sobretudo, entre o privado e o público. O aspecto transcendental apresentase primeiramente ao indivíduo. Em sua experiência religiosa, o indivíduo tende a se voltar para o sagrado e para o divino, em muitos casos, identificado com a sua vida particular e com sua própria interioridade. Esse é o lado subjetivo e privado da fé religiosa, tolerado e respeitado, inclusive, pelos Estados modernos. Entretanto, as religiões almejam igualmente construir comunidades e até civilizações universais. Nesse caso, não se separa o público do privado, o sagrado do político. Essa dimensão é atualmente rejeitada pelo ocidente secularizado, pós-westfaliano. O que o ocidente não percebe, no entanto, é que a cristandade medieval não era apenas um corpus de doutrinas e crenças dogmáticas (THOMAS, 2006, p. 37). O que se defendia com as guerras das religiões pré-westphalianas não eram apenas as doutrinas e as crenças religiosas, mas uma ideia sagrada de comunidade compreendida através da religião.

Mas como essa ideia de sagrado deve apresentar-se para os Estados? Para tentar esclarecer essa questão, utilizaremos em nossa reflexão a distinção entre religião dogmática e religião formal, presente no texto "Religião e Política", publicado pelo filósofo Eric Weil na revista Confluence: An International Forum, em 1955, dirigida à época por Henry Kissinger 5 .

\section{Religião dogmática e religião formal segundo Eric Weil}

Eric Weil aceita em princípio as teses hegemônicas do mundo pós-westphaliano. O Estado tem autonomia diante das religiões, as quais devem se ocupar apenas do âmbito privado. Na verdade, acrescenta Weil, as ideias "de neutralidade política (ou neutralidade da política) e da autonomia da religião e da moral não são invenções próprias de nossa época. Elas estão presentes na De Civitate Dei de Santo Agostinho, como estão presentes na distinção feita pelo Novo Testamento entre as coisas que pertencem a Deus e aquelas que pertencem a Cesar" (WEIL, 1993, p. 108-109.

\footnotetext{
${ }^{5}$ Religion and Politics, em Confluence: An International Forum, IV, n. 2 (1955), p. 202-214; citaremos aqui a tradução francesa de L. Nguyen-Dinh, publicado em Cahiers Eric Weil IV, Lille: Presses Universitaires de Lille, 1993, p. 103-114.

\begin{tabular}{|l|l|l|l|l|}
\hline Q Rovista Dialectus & Ano 4 & n. 11 & Agosto - Dezembro 2017 & p. 297 - 309 \\
\hline
\end{tabular}
}


A questão é saber o que exatamente pertence a Deus e o que é de César. As ideias, os valores, tudo isso que dá sentido à vida humana, encontra-se fora do domínio da política. As Igrejas e as organizações religiosas têm indubitavelmente uma função importante na política, não porque participam diretamente do poder político, mas porque, como forças profundas, influenciam o pensamento do cidadão e suas escolhas políticas. O que as religiões precisam buscar, antes de tudo, não é o poder, mas a liberdade, para que os indivíduos ajam de acordo com suas convicções, respeitando a autonomia da política e do Estado.

Com o processo de laicização e de secularização no ocidente, o conflito não é mais entre o Estado e as Igrejas, mas entre o Estado e o que se chama de consciência individual, voltada, essencialmente, para os valores últimos da vida. Desse modo, o campo de batalha não é mais pelo poder temporal, mas pela consciência dos homens. Um ponto, ao menos, apresenta-se como claro. Tanto os Estados democráticos liberais como as Igrejas concordam que os homens não podem viver sem uma crença subjetiva, sem qualquer valor que não seja apenas um meio, mas um fim em si. É necessário, portanto, estabelecer um acordo.

Esse "acordo" pressupõe uma base comum, pensada já por S. Agostinho: o conceito de paz. Santo Agostinho, que conheceu a pax romana, levou esse conceito para o mundo cristão. Todas as nossas discussões políticas e religiosas giram em torno desse ponto. É a paz que dá sentido aos projetos políticos e aos movimentos religiosos (cf. WEIL, 1993, p. 109-110).

A partir desse ponto, Weil apresenta, no final do artigo, uma importante distinção - essencial para a relação Religião e Política e, em particular, para a Teoria das Relações Internacionais -, entre a religião tradicional, teológica e dogmática, e a que ele denomina de religião formal, secularizada. Na verdade, a religião é formal apenas para a sociedade moderna. Em si mesma, ela é sempre dogmática e teológica. Entretanto, é um fato que as religiões almejam ser reconhecidas pela sociedade. Por isso, querem que seus conteúdos tradicionais sejam razoavelmente válidos. Ao nível formal, elas estabelecem, portanto, a paz, a verdade, a justiça e a liberdade como critérios razoáveis últimos da comunidade.

A questão é saber até que ponto a religião está realmente propensa à paz. Devemos relembrar aqui uma das principais consquistas da paz de Westphália: a prática da tolerância ou, mais precisamente, o direito à tolerância. Não se pode ter tolerância

\begin{tabular}{|l|l|l|l|l|}
\hline Q Rovista Dialectus & Ano 4 & n. 11 & Agosto - Dezembro 2017 & p. 297 - 309 \\
\hline
\end{tabular}


com quem não exerce a tolerância. A tolerância só é possível quando ela é recíproca. A tolerância significa que a discussão é o único método pela qual os grupos ou religiões poderão eventualmente mudar suas convicções. Se um indivíduo ou um grupo religioso não está pronto para se submeter à discussão segundo as leis bem conhecidas e determinadas pela sociedade e pelo Estado que o representa, ele pode até ser tolerado, mas não tem nenhum direito à tolerância.

Nota-se, então, que o conceito formal de religião não é assim tão formal como parece. Apesar de visar a paz universal e de tê-la como instrumento principal para a transmissão de sua mensagem, toda religião possui um conteúdo particular. Este pode, em alguns momentos, descambar para a intolerância e para a prática da violência. $O$ mesmo pode ser dito em relação ao Estado. Por exercer o monopólio da violência, o Estado moderno também é propenso ao exagero. Tanto o Estado como as religiões mantêm um vínculo estreito com a violência. Isso faz com que a Religião e a Política estejam sempre ligadas, apesar do abismo que há entre ambas (cf. WEIL, 1993, p. 111112).

\section{Considerações finais}

Weil pensa a partir da religião cristã. Mas os princípíos são análogos às demais religiões. As Teorias das Relações Internacionais podem e devem acolher a ação religiosa em seu meio, como um tipo de força profunda, agindo sobre os atores internacionais. Ademais, o Estado moderno não pode simplesmente destruir os sagrados religiosos das comunidades, como almejou fazer o tratado de Westphália. A diferença, em relação ao mundo pré-westphaliano, é que não existe nas comunidades modernas espaço para uma religião única. Essa concepção, típica da cristandade e dos califados islâmicos medievais, foi rejeitada pelos Estados nacionais modernos. O que deve ser defendido aqui, do ponto de vista formal, isto é, sem considerar os conteúdos religiosos em si, é um pluralismo religioso e moral, em vista da paz e da justiça.

Sabe-se que os teóricos das relações internacionais têm dificuldades em aceitar os pontos de vista dos historiadores e vice-versa. Em alguns casos, se comportam como verdadeiros inimigos declarados. É o que diz Brunello Vigezzi: “os historiadores e os teóricos (...) têm prazer em definir suas disciplinas como diretamente opostas. A 'história' recusa os esquemas da teoria; a 'teoria' afirma que superou o culto inútil de detalhes que caracteriza a história" (2000, p. 461-462). Em nossa opinião, os limites da

\begin{tabular}{|l|l|l|l|l|}
\hline Govista Dialectus & Ano 4 & n. 11 & Agosto - Dezembro 2017 & p. $297-309$ \\
\hline
\end{tabular}


"história" e da "teoria" tornam-se patentes diante das experiências religiosas e de suas influências crescentes na política e nas relações internacionais. Para uma melhor compreensão dessa realidade, acreditamos que tanto os teóricos precisam do "material" oferecido pelos históriadores quanto estes precisam das "análises" daqueles.

É verdade que a comunidade internacional é ameaçada por "choques de civilizações", tais quais foram expostos por Samuel P. Huntington. Mas essa não é toda a verdade. Existem sim fundamentalistas cristãos e fundamentalistas muçulmanos, mas têm também aqueles que desejam construir uma nova humanidade, segundo valores universais, além dos conteúdos religiosos e das doutrinas políticas radicais. É o próprio Robert Frank que afirma isso no final de seu artigo: além das diferenças culturais e religiosas, o humanismo aparece como uma grande esperança para todos os povos (FRANK, 2012, p. 434-435). Ora, é justamente o aspecto transcendental irredutível da fé religiosa que permite essa ação histórica dos valores humanos universais sobre os Estados modernos. Mais precisamente, é esse aspecto transcendental dogmático da fé que possibilita compreender as religiões como um tipo de forces profondes sobre os Estados e os demais atores políticos internacionais.

\section{Referências Bibliográficas:}

CORALLUZZO, V. OZZANO, L. (Orgs). Religioni tra pace e guerra. Il Sacro nelle relazioni internazionali del XXI secolo. Milão: UTET Università, 2012.

DUROSELLE, J-B. Todo império perecerá. Teoria das Relações Internacionales. Brasília: Editora Universidade de Brasília: São Paulo: Imprensa Oficial do Estado, 2000.

DUROSELLE, J-B. Les Débuts du catholicisme social em France (1822-1870). Paris: Presses Universitaires de France, 1951.

FRANK, R. Pour l'histoire des relations internationales. Paris: Presses Universitaires de France, 2012.

FRANK, R. Religion (s): enjeux internationaux et diplomatie religieuse. In: FRANK, R. Pour l'histoire des relations internationales. Paris: Presses Universitaires de France, 2012, p. 407-435.

FOX, J. Religion et relations internationales: perceptions et réalités. In: Politique étrangère, 2006/4, p. 1059-1071.

HATZOPOULOS, P.; PETITO, F. (Orgs). Ritorno all'esilio. La religione nelle relazione internazionale. Milão: Vita e Pensiero, 2006.

\begin{tabular}{|l|l|l|l|l|}
\hline Q Rovista Dialectus & Ano 4 & n. 11 & Agosto - Dezembro 2017 & p. $297-309$ \\
\hline
\end{tabular}


HUNTINGTON, S. P. O choque das Civilizações e a mudança na Ordem Mundial. Lisboa: Gradiva, 2009.

KUBÁLKOVÁ, V. Verso una Teologia Politica Internazionale. In: HATZOPOULOS, P.; PETITO, F. Ritorno all'esilio. La religione nelle relazione internazionale. Milão: Vita e Pensiero, 2006, p. 99-133).

RENOUVIN, P. La crise européenne et la primière guerre mondiale. Paris: Presses Universitaires de France, 1948.

RENOUVIN, P.; DUROSELLE, J-B. Introduction à l'histoire des relations internationales. Paris: Armand Colin, 1991.

THOMAS, S. M. Prendere sul serio il pluralismo religioso e culturale. In: HATZOPOULOS, P.; PETITO, F. Ritorno all'esilio. La religione nelle relazione internazionale. Milão: Vita e Pensiero, 2006, p. 31-69.

VIGEZZI, B. "Teóricos" e "historiadores" das relações internacionais. In: DUROSELLE, J-B. Todo império perecerá. Teoria das Relações Internacionales. Brasília: Editora Universidade de Brasília: São Paulo: Imprensa Oficial do Estado, 2000, p. 461-483.

WEIL, E. Religion et politique. In: Cahiers Eric Weil IV. Lille: Presses Universitaires de Lille, 1993. 103-114.

\begin{tabular}{|l|l|l|l|l|}
\hline Qovista Dialectus & Ano 4 & n. 11 & Agosto - Dezembro 2017 & p. 297 - 309 \\
\hline
\end{tabular}

